Mari Teresinha Alminhana Panni

Claudia Glavam Duarte

\title{
A "docência-sabot" e as fissuras curriculares nas aulas de matemática em uma classe Multisseriada
}
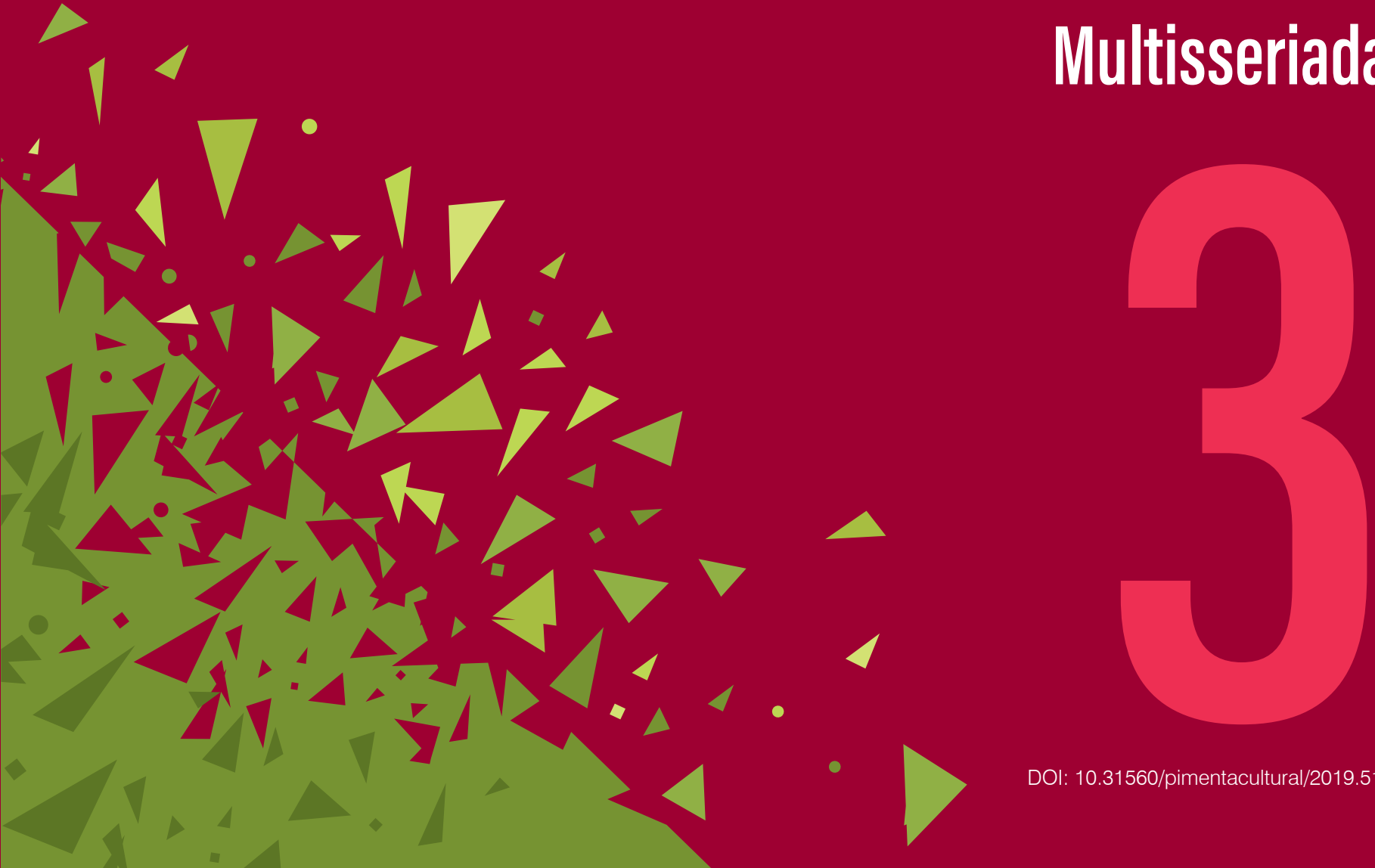


\section{Introdução}

O presente texto é resultante da Dissertação de Mestrado intitulada: "Tensionamentos no Dispositivo da Seriação: a matemática escolar no contexto multisseriado" do Programa de Pós-Graduação em Ciências, Química da Vida e Saúde da Universidade Federal do Rio Grande do Sul. Tal pesquisa ocorreu na Escola Estadual de Ensino Fundamental José Martins Correa Filho, que fica situada no Quarto Distrito de Santo Antônio da Patrulha /RS e que possuí sua organização escolar pautada no modelo multisseriado.

O interesse por esta temática emergiu através de questionamentos e problematizações sobre possíveis movimentos que poderiam ocorrer nas aulas de matemática, visto que esta disciplina tem como pressuposto organizar aprendizagens que obedecem à lógica do simples ao mais complexo, regida por um currículo homogêneo, hierárquico e com pré-requisitos (SCHMITZ, 2002). Exemplo disto é a defesa de que se aprende multiplicação somente depois da adição e que existe uma "lógica interna da matemática, dominada pela ideia de pré-requisitos" (SCHMITZ, 2002, p.115). Assim, tal lógica definiria o que vem "antes e o que vem depois" para a facilitação da aprendizagem em termos de conceitos matemáticos, tal ordem estaria articulada a "necessidade de colocar o simples antes do complexo" (Ibidem, 2002, p.114). Assim, o desejo de entender como o currículo de matemática se movimentaria dentro do contexto multisseriado, entendido aqui como um espaço múltiplo e heterogêneo, fez parte de nossas intenções de pesquisa.

1. Escola/Classe multisseriada é uma forma de organização de ensino na qual o professor trabalha, na mesma sala de aula, com várias séries simultaneamente. Refiro-me a escola multisseriada quando esta apresenta toda sua organização, todas as suas turmas, distribuídas neste modelo. No entanto, podem existir escolas que apresentem somente uma turma multisseriada, exemplo: primeiro, segundo e terceiros anos multisseriados e quarto e quinto ano seriados 
Levantamos como hipótese que a heterogeneidade das classes multisseriadas, tenderia a desestabilizar as características que determinam o currículo de matemática, principalmente a hierarquia e as separações feitas na listagem dos conteúdos a serem cumpridos para cada ano/série. Inferimos que se manter em uma ordem de acontecimentos pré-estabelecidos, entendendo-os muitas vezes como o caminho certo e "natural", talvez necessitasse de bastante esforço nessa organização, visto que esta abrigaria em um mesmo espaço/tempo, diferentes idades e anos/séries. Nesta linha de raciocínio Bauman (1999) aponta que seguir um curso tido como "natural":

\footnotetext{
[...] requer um bocado de planejamento, esforço organizado e vigilante monitoramento. Nada é mais artificial que a naturalidade; nada é menos natural do que se lançar ao sabor das leis da natureza. O poder, a repressão e a ação propositada se colocam entre a natureza e essa ordem socialmente produzida na qual a artificialidade é natural. (Ibidem, p.15)
}

Assim, entendemos que nada há de natural, tudo é arbitrário e contingente e a própria noção de natural é pura inventividade. Compreendemos que o solo em que nos movemos é frágil e por este motivo, temos que artificialmente organizar o mundo para mantê-lo estável e previsível (BAUMAN, 1999). No campo educativo não é diferente, pois "a hierarquia especulativa da aprendizagem dá lugar a uma rede de áreas de investigação, cujas fronteiras respectivas estão em constate fluxo" (DIAZ, 1998, p.27). Assim, entendemos que o estipulado como "natural" talvez pudesse sofrer algumas fissuras dentro do contexto multisseriado. Dessa forma, observar, analisar e problematizar a forma como este currículo se desenvolve e o que acontece quando adentra um espaço/tempo regido pela multiplicidade, é um dos pontos a que este estudo se propôs.

Do ponto de vista metodológico, realizar o movimento de problematização nos leva a compreender que em um contexto de pesquisa, a análise e a interpretação de um objeto pode ser lida sob diferentes lentes e esta condição faz com que tenhamos incertezas 
e suspeitas daquilo que se supunha ser o "verdadeiro" caminho, a trilha "correta" a ser seguida. Dessa forma, podemos dizer que esta pesquisa nos levou a "operar com a provisoriedade, com o transitório, com o mutante" (LOURO, 2007, p. 238). Nessa trajetória, aliada a ideia de viagem e com uma coragem erguida a cada passo, foi possível experimentar as diversas variações para seguir as rotas que foram programadas e as que foram emergindo no decorrer da pesquisa. Em outras palavras, foi no movimento da investigação, no próprio caminhar que a viagem tomou sentido através de uma rota que se formou dentro do espaço/tempo de estudos e no campo investigativo. Dessa forma, problematizar o currículo de matemática no espaço multisseriado nos levou a rotas que buscavam a "estrangeiridade como artificio criativo e rigoroso de pesquisa" (MIZOGUCHI, 2016, p. 36).

Estivemos interessadas nos encaminhamentos dados pelo professor dentro de um universo que parecia tão múltiplo e assim, nos questionávamos se eram colocadas paredes imaginárias para separação dos anos escolares ou se havia outro modo de operar com a(s) turma(s). Enfim, estes eram pontos que instigavam à problematização, pois como diz Foucault: "É preciso pensar problematicamente, mais que perguntar e responder dialeticamente" (ibidem, 2005, p. 246).

Iniciamos esta trajetória com a intenção de construir possibilidades de um pensar diferente do que vinha sendo pensado sobre o currículo de matemática em classes multisseriadas. Dito de outro modo, pretendíamos tensionar o que sabíamos ou o que imaginávamos saber sobre o contexto educativo que se pauta por essa organização escolar nas aulas de matemática. No limite, podemos dizer que, tratava-se de suspender as "verdades" que nos atravessavam para entendermos que "só existem perspectivas-múltiplas, divergentes, refratárias à totalização e à integração" (CORAZZA; TADEU, p.40, 2003). Assim, desconfiamos de certas perspectivas 
que devido à força que possuíam nos capturavam e levavam-nos a pensar que tal modelo de organização escolar era "ultrapassado" e só existiria devido a condições extremamente adversas: número reduzido de alunos falta de professores, entre outros.

Dessa forma, este trabalho foi construindo um caminho investigativo pautado em anotações em um caderno de campo, entrevistas e observações feitas na escola pesquisada entre os anos de 2017 e 2018. Foram várias idas e vindas no processo de configuração deste estudo, pois seguidamente era necessário reescrever as análises e voltar à escola para rever e perguntar algumas situações que ficaram suspensas. Toda esta movimentação compactua com as palavras de Meyer e Paraíso (2012), quando afirmam que: "o mais potente desses modos de pesquisar é a alegria do ziguezaguear". (Ibidem, p. 17) E assim, para acompanhar-nos nesta empreitada buscamos em Michel Foucault, ferramentas que pudessem nos instrumentalizar para a realização da análise deste estudo. Assim, para seguir essa caminhada, também contamos, durante a trajetória, para o entendimento e uso de tais ferramentas, não só do próprio filósofo, mas também de alguns trabalhos produzidos por comentadores de Foucault, principalmente, aqueles que se vinculam a área educacional.

\footnotetext{
Michel Foucault oferece inúmeras ferramentas, teóricas, metodológicas e mesmo temáticas, para nossos estudos em educação: as práticas de vigilância na escola, a construção disciplinar dos currículos, as relações de poder no espaço da sala de aula, a produção de sujeitos confidentes - são apenas alguns dos muitos temas que há pelo menos dez anos têm sido estudados em nossa área, com base no pensamento do filósofo. (FISCHER, 2003, p. 372)
}

Dessa forma, apresentamos nesse texto, o entendimento de como a disciplina de matemática se desenvolve dentro de uma classe multisseriada. Aliado a isso, também buscamos perceber os encaminhamentos dados pelo professor nas aulas, pois entendíamos que a partir das multiplicidades da sala de aula, poderiam emergir novas formas de se pensar/fazer educação. 


\title{
Organização multisseriada: a matemática e os seus pré-requisitos
}

As escolas que abrigam a multisseriação como forma de organização dos tempos/espaços escolares, estão em sua quase totalidade, vinculadas às áreas rurais e torna-se na maioria das vezes, a única opção ao sistema escolar de sujeitos que lutam para manter a escola em suas comunidades. Dessa forma, a organização mulisseriada é vista como um arranjo, pois o lócus do território educacional da multisseriada está vinculado a,

\begin{abstract}
Uma representação social que as colocam em gradiente de inferioridade em relação às escolas urbanas seriadas. Inferioridade forjada pelo pressuposto de que a escola urbana seria hierarquicamente superior." (DUARTE, TASCHETTO, 2014, p. 52).
\end{abstract}

Nesta perspectiva, estas escolas são vistas muitas vezes, como "escolinhas", cuja organização partiria única e exclusivamente do pressuposto da economicidade de professores e de espaço físico para as Secretarias de Educação. Na esteira dessa premissa não representaria, muitas vezes, para os órgãos educacionais, algo que se devesse considerar do ponto de vista pedagógico, seria somente um arranjo necessário para suprir uma necessidade devido à quantidade de alunos que se apresentam em algumas comunidades, muitas delas carentes, ou seja, a "única alternativa para os sujeitos estudarem nas comunidades rurais em que vivem" (HAGE, 2014, p.1173). Ademais, esta relação de inferioridade também é projetada por aquilo que, muitas vezes é entendido como o modelo ideal para a organização escolar, ou seja, o modelo seriado.

Acompanhando o referencial que nós escolhemos, compreendemos a seriação, pelo fato de distribuir as crianças por idade nas diferentes séries escolares, como um dispositivo. Segundo Foucault (2000) o dispositivo é: 
[...] um conjunto decididamente heterogêneo que engloba discursos, instituições, organizações arquitetônicas, decisões regulamentares, leis, medidas administrativas, enunciados científicos, proposições filosóficas, morais, filantrópicas. Em suma, o dito e o não dito são os elementos do dispositivo. O dispositivo é a rede que se pode tecer entre estes elementos (Ibidem, 2000, p. 244)

Assim, o Dispositivo da Seriação organizaria uma série de elementos diferentes, tais como: a arquitetura escolar que deve abrigar diferentes salas de aula, uma para cada ano escolar, o currículo escolar definido para cada faixa etária, os discursos de especialistas que afirmam as potencialidades e fragilidades de cada período da infância, entre outros. Dessa forma, o Dispositivo da Seriação dita as regras e exige certas configurações para afirmar como deve ser a organização das escolas. Pontuamos aqui, que o dispositivo se configura em um conjunto de elementos, que segundo Foucault (2008, p. 138) "[...] está sempre inscrito em um jogo de poder, estando sempre, no entanto, ligado a uma ou a configurações de saber que dele nascem, mas, que igualmente o condicionam", ou seja, o dispositivo é como algo que disparasse uma malha cheia de entrecruzamentos, que dispara e faz com que certas coisas ocorram.

S U M Á RIO

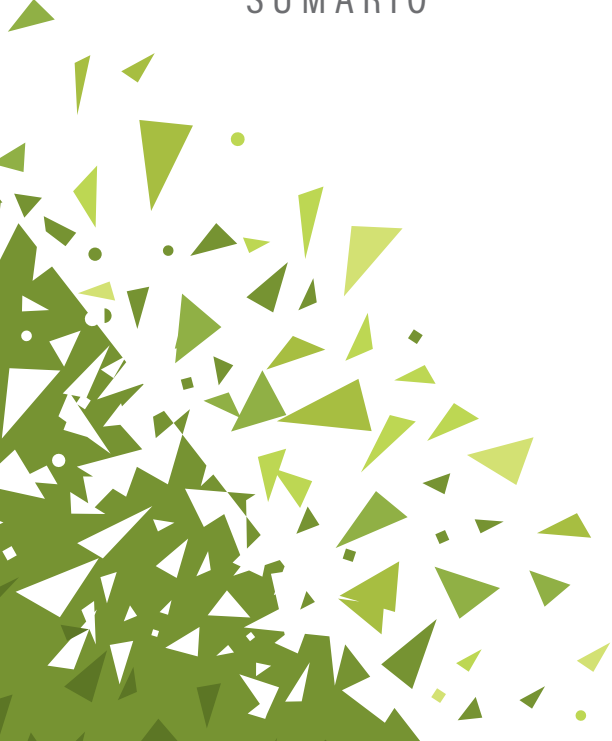

No entanto, esta malha ao entrar em contato com o modelo multisseriado encontra algumas resistências. Dessa forma, compreendemos que a multisseriação funciona como um contradispositivo que tende a exercer certa força que embaralha os códigos e fissura e ou atrita a ordem estabelecida pelo modelo da seriação. Como diz Mizoguchi (2016) o contradispositivo "opera de forma contrária ao estabelecido, rompe as estruturas criando novas linhas das precedentes escapa, enfim, as urgências diretivas e diretas do saber e do poder" (Ibidem, p.94). Na esteira destas premissas, desconfiamos que talvez algo ocorresse no currículo de matemática desenvolvido nesta escola, tal des-confiança foi possível porque o conceito de currículo que perpassa nosso entendimento está ancorado na concepção de Corazza (2001) que o entende: 
[...] como uma linguagem, nele identificamos significantes, significados, sons, imagens, conceitos, falas, língua, posições discursivas, representações, metáforas, metonímias, ironias, invenções, fluxos, cortes.... Assim como o dotamos de um caráter eminentemente construcionista. (Ibidem, p.9)

Nessa perspectiva, o currículo é construído por linguagens de bases históricas e sociais e que por este motivo, é arbitrário e ficcional (CORAZZA, 2001), é pura inventividade. Fazemos uso das palavras da autora para pensar que o currículo se constitui por regras que, a partir das teorias de especialistas, justificam os objetivos que devem ser alcançados para cada etapa do ensino, viabilizando a construção de determinados tipos de sujeitos.

Sob a mesma perspectiva teórica, Tomaz Tadeu da Silva (2010) destaca que talvez o mais importante para destacar na definição de currículo "seja de saber quais questões uma "teoria" do currículo ou um discurso curricular busca responder". (Ibidem, 2010, p.14). Corazza (2001) parece ter definido essa problemática por intermédio do provocativo título de seu livro que pergunta: "o que quer um currículo?" A resposta já aparece de imediato indicando que o currículo tem fome de sujeito, quer forjar certos tipos de subjetividades. Por este motivo, pode-se inferir que o currículo é campo de luta, campo de exercício de poder, pois se trata de uma linguagem que "ao corporificar narrativas particulares sobre o indivíduo e a sociedade, nos constitui como sujeitos - e sujeitos também muito particulares". (SILVA, 1998, p. 195)

Nesta perspectiva, os "sons, imagens, conceitos, falas", entre outros que compõem o currículo escolar, são construções contingentes e arbitrárias. Especificamente no que tange aos conceitos, os chamados conteúdos disciplinares, diríamos que estes se justificam não somente pela lógica interna da área ao qual pertencem, mas principalmente nas articulações que possibilitam fazer com as exigências do campo social mais amplo (SARTORI, 2015). Sendo 
assim, o motivo pelo qual tal conteúdo é escolhido e outros não, se direcionam a outro questionamento, "o que eles ou elas devem ser? " (SILVA, 2010, p. 15). Com essas premissas, se formam as estruturas que definem a que um currículo se propõe, ou seja, o currículo é construído por parâmetros que estipulam o sujeito ideal para determinada sociedade, "o currículo é simplesmente uma mecânica" (SILVA, 2010, p. 24) que movimenta a maquinaria que organiza as estruturas educacionais de acordo com padrões estabelecidos.

É apenas uma contingência social e histórica que faz com que o currículo seja dividido em matérias ou disciplinas, que o currículo se distribua sequencialmente em intervalos de tempo determinado, que o currículo esteja organizado hierarquicamente. (SILVA, 2010, p.148)

Pensando assim, especificamente no currículo de matemática, Santos (2009) nos convida a problematizar esta matemática que ela denomina de "etapista", ou seja, aquela que se desenvolve a partir de etapas hierárquicas bem definidas. A autora corroborando com a ideia de que o currículo está interessado na construção de determinados tipos de sujeitos, aponta para a necessidade de abrirmos a possibilidade para a "formação de outros "EUS" (SANTOS, 2009, p. 97) ". Talvez sejam estes outros "EUS" que percebemos se configurando no modelo multisseriado, pois "não há na subjetividade uma forma única, aplicável a todos/as. Nela nada há de privado" (CORAZZA, 2001, p.62). Assim, tal organização que agrupa idades e anos diferentes em um mesmo espaço/ tempo, acaba fissurando o que é estabelecido como "adequado" para aprender em cada etapa escolar. Frente a estas constatações que circundam a educação matemática é que julgamos pertinente a análise de possíveis fissuras, engendradas pelo modelo multisseriado nas aulas de matemática. Assim, lançamos como hipótese que seria mais fácil identificar a existência ou não de rupturas em algo que nos parecia bastante demarcado. 


\section{A "docência-sabot" fazendo artes/arteiras nas aulas de matemática}

Durante as idas a campo, percebemos a possibilidade de constituição de uma docência que pode propiciar o rompimento das relações de uma organização educacional hierarquizada, que se produz em um sistema pré-estabelecido com tendências homogeneizadoras. Assim, o que muitas vezes foi percebido se configurava em uma docência que, com suas manobras tendia a bagunçar o estabelecido e mexer com o que estava programado, deixando rastros por onde passava através das suas metodologias desconectadas da linearidade e do homogêneo. Frente a essas proposições, julgamos que esta docência tendia ao novo, ao inusitado e desprendia inquietações sobre esta forma desconcertante de ser professor dentro de um sistema educacional hierarquizado. Nomeamos esta docência de: docência-sabot.

Ao percorrer a origem etimológica da expressão "sabotagem", verificamos que esta provém da língua francesa "sabot" que significa "tamanco". A articulação com o entendimento de sabotagem, enquanto ato proposital que danifica, que impede o funcionamento de certos mecanismos, que prejudica algo de forma voluntária está associado ao período da Revolução Industrial, especificamente ao ato de trabalhadores que, descontentes com suas condições laborais, colocavam seus tamancos nas máquinas das fábricas para causar-Ihes danos e paralisações. Silvo Gallo (2003), ao reter a imagem de tais grevistas nos instiga a agir, no campo educacional, como "ludistas pós-modernos"1, sua intenção com esta provocação é impedir a máquina de funcionar, danificar e estancar o automatismo das ações contra os efeitos de uma educação maior

1. Silvio Gallo (2003) busca inspiração no operário de uma fábrica têxtil Ned Ludd que destruiu totalmente os teares mecânicos de uma fábrica num sinal de revolta contra os efeitos da Revolução Industrial no início do século XIX. 
entendida como aquela baseada nos "[...] planos decenais e nas políticas públicas de educação, dos parâmetros e das diretrizes, aquela da constituição e da Lei de Diretrizes e Bases da Educação Nacional, pensada e produzida pelas cabeças bem-pensantes a serviço do poder". (GALLO, 2003, p. 78). Assim, tal ato, quando pensado no âmbito da educação, nos remete à relação de forças no embate entre a educação maior e a educação menor1, pois as táticas da educação menor são bastante similares as dos grevistas que trabalhavam nas fábricas (GALLO, 2003).

Neste sentido, acreditamos que talvez, uma das condições necessárias para pensarmos outro tipo de educação seja uma docência-sabot que se movimenta "fazendo arte-arteiramente" contra a maquinaria escolar. No limite, é uma docência que institui micro-revoluções "como aqueles sindicalistas norte-americanos do começo do século, que pegavam um trem para o Oeste e que, a cada estação atravessada, paravam para fundar uma célula, uma célula de luta" (NEGRI, 2001, p.24). Nossa hipótese é a de que esta docência que "emperra" a máquina ou que, minimamente, deforma a esteira de produção afirmando uma educação que,

\section{S U MÁRIO}

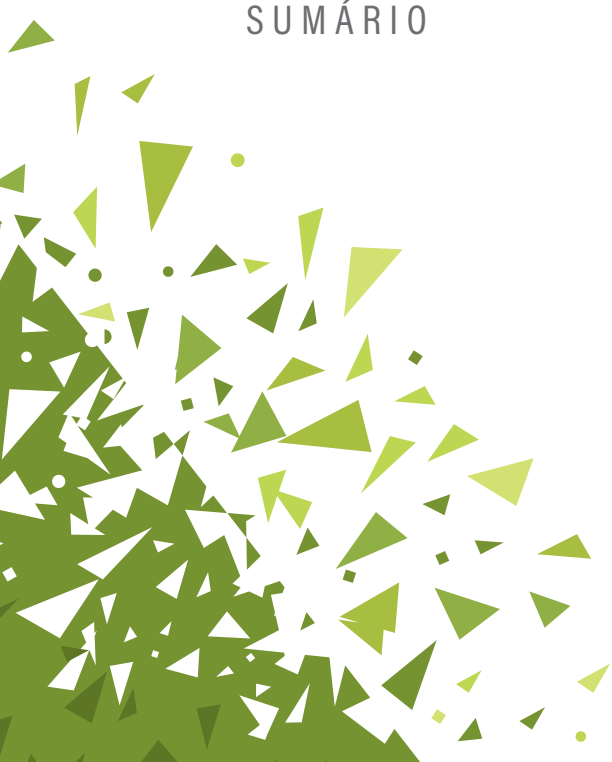

[...] não está subordinada à representação, à adequação da verdade, ao dado, antes disso, os instrumentos para pontuar os traços vitais para a Educação percorrem movimentos de forças, de resistências, que podem deformar a forma estabelecida por currículos escolares, saberes prontos, conhecimentos interpretados que desejam modulação universal. Com isso, seria possível compor cores novas e vibrantes ao novo corpo que deseja nascer, um corpo alegre, desejante [...] (BRITO, 2015, p. 57)

Tal deformação poderia ser acionada por dois movimentos: primeiro aquele que estanca a maquinaria e segundo aquele que a faz ir diferindo de sua função calcada nas leis e interdições e que,

1. Segundo Silvio Gallo (2003, p. 78) "a educação menor é um ato de revolta de resistência. Revolta contra os fluxos instituídos, resistência às políticas impostas; sala de aula como trincheira, como a toca do rato, o buraco do cão. 
em efeito vai produzindo outras formas de subjetivação docente. Como diz Zordan (2013):

\begin{abstract}
A subjetivação produz as formas, embora seja um processo sem forma, visto que é substanciada por forças que perpassam as formas, dinamizando suas estruturas e estabelecendo relações de poder. Este processo pode ser coletivo ou individual, acontecendo sempre que a força se "dobra" sobre si mesma, fazendo com que o poder se exerça sobre "si". (Ibidem, 2013, p. 1160)
\end{abstract}

Nesta perspectiva, apostamos que uma sala de aula diferenciada, a multisseriada, poderia se constituir em um território propício ao confronto do professor com as relações de força que o conformam a ser, pensar e agir dentro das normas estabelecidas pela seriação. Dito de outra forma, a existência de escolas/classes multisseriadas poderia ser tomada como uma condição propícia no sentido de ali se fazer germinar uma docência-sabot que reaja aos modelos totalitários e homogeneizantes, pois o docente vivenciaria embates cotidianos, visto que esta configuração "destitui a série como princípio ordenador e como fundamento para as ações pedagógicas" (DUARTE; TASCHETTO, 2014, p.53) e provoca abalos em uma zona de conforto historicamente construída e naturalizada.

Assim, a continuidade do trabalho de campo nos fez perceber micro movimentos, estas pequenas revoltas diárias de que nos fala Larrosa (2000), pois identificamos que, muitas vezes, os professores não separavam os alunos, apesar de a sala conter três diferentes anos escolares (o primeiro, o segundo e o terceiro anos). Nossa hipótese inicial era a de que os alunos seriam separados por fila: a fila do primeiro ano, do segundo, etc. No entanto, a racionalidade que imperava parecia não querer instituir classificações e hierarquizações, como afirmou um professor: eu procuro nem fazer essa divisão na minha cabeça sabe? Porque eu sei que ela não vai dar certo! Ao questionar sobre este fato as respostas foram as seguintes: 
[...] eu não impeço eles de interagirem um com o outro, ou de certa forma, o Arthur no ano passado (segundo ano) e outro coleguinha (terceiro ano), que às vezes eles estavam fazendo um problema de multiplicação e ele dizia: o fulano quanto que é, tanto vezes tanto? Há é tanto... [Grifos nossos]

Aí professor posso tentar fazer aquela lá também? Claro pode tentar fazer... Eu não posso deixar de provocar ele, ou fazer com que ele em certo momento ajude aquele outro aluno a resolver aquele problema, porque ele também está aprendendo. [Grifos nossos]

[...] nós somos uma turma, não interessa série, só que isso ainda é um vício do próprio professor, o segundo ano, terceiro ano, a fila ou alguma coisa assim, isso eu acho que as instituições têm que começarem a se organizarem, para que isso em uma multisseriada fique claro que é uma turma, a turma, e não são várias turmas que tenho ali. [Grifos nossos]

Daí eu vi que ele sabia os nomes dos números, que ele sabia essa classificação de unidade, dezena centena e milhar ...então aquilo ali eu fui dando e fui vendo que ele sabia e fui e fui indo, recapitulei com o quinto, porque vou saber se o quinto ainda se lembra o que leu, se não ficou nada e aí fui indo, fui indo... o que dá certo dá, o que não dá eu volto, porque tem uns que, as vezes os do quinto, tem umas do quinto que as vezes precisam de mais atenção, eles conseguem trabalhar em grupo e desenhar todo mundo junto no mesmo cartaz, assim uns quatro, cinco. Eu não consigo assim, eu procuro nem fazer essa divisão na minha cabeça sabe? Porque eu sei que ela não vai dar certo. [Grifos nossos]

Neste sentido, a hierarquização e os pré-requisitos que formam a estrutura do ensino de matemática, em algumas vezes, são fissurados pelos encontros que ocorrem dentro do processo de ensino e aprendizagem na sala de aula, pois o professor não coloca regras, ele apresenta o conteúdo e deixa os acontecimentos nortearem o processo sem separações, ele vai seguindo na direção do que "dá certo, dá e o que não dá, volta". Dessa forma, vez que outra, dentro deste processo de tatear até dar certo, sob o descuido do Dispositivo da Seriação, as aulas de matemática ensaiam fissuras na suposta linearidade e na necessidade de pré-requisitos para a efetivação das aprendizagens da matemática. Sendo assim, utilizando a ideia de Foucault (2000) esta forma de aprender, "agita o 
que se percebia imóvel; ela fragmenta o que se pensava unido; ela mostra a heterogeneidade do que se imaginava em conformidade consigo mesmo" (Ibidem, p. 15).

Dessa forma, os professores quando ensinavam matemática, pareciam minimizar a força da premissa que afirma que "a listagem dos conteúdos também tem o poder de determinar a ordem ou sequência em que esses conteúdos "devem" ser ensinados" (SCHMITZ, 2002, p.114). Pareceu-nos que a sequência e a ordem eram fissuradas pela metodologia do "tatear", do "fui indo, fui indo".

[...] pedi que quatro meninos [do primeiro ano] pegassem, por exemplo; três pecinhas cada um e botassem dentro da caixa. Eles foram lá e contaram e observaram a contagem deles para ver se contaram certo e botaram na caixa e..... Fechei a caixa né, então perguntei para eles, tanto para o primeiro, segundo e terceiro, perguntava aleatoriamente, para ver o conhecimento deles, para eles darem a ideia de quanto teria dentro daquela caixa, só observando, então alguns iam dizendo os valores e no decorrer dessa atividade deu para observar que alguns já iam apontando para os colegas para ter a contagem do valor exato. [Quem respondeu ao questionamento foi uma menina do primeiro ano, após fazer sua própria contagem mentalmente, explicando que tinha quatro meninos com três pecinhas... ou seja, três vezes quatro]. $E$ assim, teve uma hora, deu para notar também que ela contou e ela achou o resultado e quando perguntei para os outros eles falaram que não era o resultado certo, aí ela começou a pensar e começou a contar de novo e disse assim: Professor é doze? Tipo assim ela contou e deu de novo o resultado dela, e era doze, mas como os outros falaram outro resultado ela ficou na dúvida. [...] Daí tu imagina, pode dizer não é para você aprender ainda só porque é multiplicação? [Grifos nossos]

Entendemos que a desconfiança de que os cálculos feitos pela menina estivessem corretos, fazia parte de uma estratégia do Dispositivo da Seriação, pois pairava a dúvida de que uma menina do primeiro ano pudesse resolver situações matemáticas destinadas ao terceiro ano. Talvez o fato de presenciar, por diversas vezes, situações que envolviam o conceito de multiplicação tenha possibilitado a resolução da questão. Tal suposição advém também da 
leitura do texto "A Conversar com as Estátuas" de Duarte e Taschetto (2014, p.54) que afirma que no espaço multisseriado "não dá para tapar os ouvidos das crianças", as crianças acabam se envolvendo em aprendizagens que a princípio não seriam destinadas a sua idade e ano escolar. Assim, o professor parecia proporcionar aos alunos a experiência de aprender, de vivenciar e de poder sentir as coisas, mesmo que tais crianças não se constituíssem nos "corretos destinatários", dito de outro modo, tratava-se de uma docência que "não reduz o acontecimento, mas o sustenta como irredutível." (LARROSA, 2011, p. 6). Uma docência-sabot.

Assim, a interação, a provocação e o tatear o caminho "e fui e fui indo", pareciam ser os alicerces de uma prática que se constituía ao fazer-se. Parecia não existirem certezas, pontos exatos de chegada e a "não divisão", instituía uma docência que, em meio a um caos, fazia sucumbir à relação de força que buscava estruturar a educação maior em idade/ano escolar. Ocorreria aí uma situação que movimentaria mais o devir em relação ao dever? Acreditamos que sim, pois o processo educativo parecia se movimentar em torno dos encontros, de uma educação sem imagens fixas, que é "retirada do campo das modelações para as modulações, variações, encon-

S U M ÁR I 0

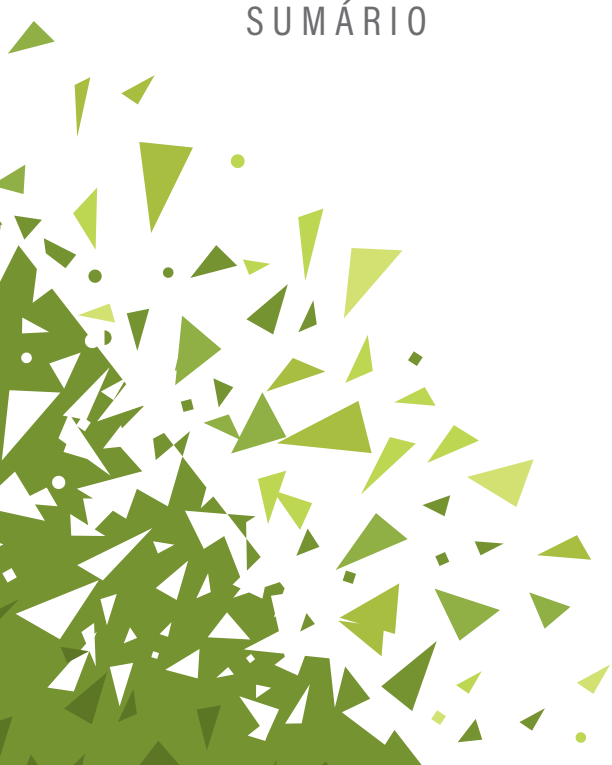
tros, interseções [...]" (BRITO, 2015, p. 39). Não havia garantias do ponto de chegada, tratava-se de um movimento de ziguezaguear "e aí fui indo, fui indo... o que dá certo dá, o que não dá eu volto", que seguia o fluxo determinado pelo instante em que se efetuava. Dito de outra forma, eram os movimentos instituídos no momento, os condicionantes para prosseguir caminhando e estas pequenas incisões/sabotagens na estrutura, parecia danificar os automatismos da maquinaria escolar que delimitava as aprendizagens em função da idade do aluno. Assim, a pretensão de classificações e hierarquizações encontravam obstáculos em uma turma multisseriada, pois havia encontros, interações e movimentos de classes que ora se agrupavam de uma determinada forma, ora de outra e o arrastar de cadeiras mostrava a intensidade de tais encontros. 
Assim, não encontramos em nossa investigação uma identidade de grupo: grupo do primeiro ano, do segundo ano, etc, mas encontros, afinidades que surgiam e se desfaziam, eram momentâneos. No entanto, às vezes o fluxo era contido, talvez uma artimanha do Dispositivo Seriado fazendo força para recuperar o seu lugar e retomar seu espaço. Tal afirmação se baseia no fato de que, em alguns momentos, o professor justificava a formação de grupos heterogêneos a partir de sua concepção de "níveis de aprendizagem".

[...] isso, aí vamos dizer assim, eu vou trabalhar com os números decimais, a partir de um jogo onde todos eles podem jogar o mesmo jogo, porém a cobrança deles vai ser em níveis diferentes, não interessa se ele é do primeiro, segundo ou terceiro, a partir do momento que ele conseguir realizar o objetivo ele vai partir para o outro, se eu vejo que ele não consegue, por exemplo, contar o jogo com os dados, ele não conseguiu contar o valor numérico, ele tem que continuar trabalhando aquele valor ali, só que dentro do jogo eu trabalho o valor, mas também tem que trocar a unidade por dezena, entendeu? De acordo com a pontuação que vai fazendo. [Grifos nossos]

[...] o aluno que tem dificuldade, ele vai precisar de ajuda daqueles colegas [...] então o meu papel, os dos próprios alunos é ajudar ele a fazer junto com o grupo [...] ora por aproximação de níveis, ora por níveis diferenciados, porque eles terminam a atividade $e$ perguntam: professor posso ajudar o outro colega? - Mas tu sabes como o professor pergunta as coisas para ele - há eu sei professor, então posso ajudar ele? Eles vão reproduzindo aquilo que eu questiono com os próprios colegas, mas pensa nessa letra aqui, será que começa com ela? .... Vai ali no cartaz, será que é essa, será que não é? Então eles também não estão ali dando respostas... [Grifos nossos]

Dessa forma, em alguns momentos o Dispositivo da Seriação fazia imperar situações cotidianas ao modelo seriado. Entendíamos que, de vez enquanto, pareciam ser colocados biombos, paredes imaginárias na sala que tentavam separar os anos escolares em níveis de aprendizagem. Como afirma Bauman (1999), a classificação é o modo de evitar o desconforto da desordem, é proporcionar ao mundo uma ordenação, é, "manipular suas probabilidades, tornar alguns eventos mais prováveis que outros, comportar-se 
como se os eventos não fossem casuais ou limitar ou eliminar sua casualidade" (Ibidem, 1999, p.9). Assim, a classificação por níveis parecia querer ordenar o espaço da aula e prover-Ihe uma estrutura.

No entanto, percebemos que estes arranjos, muitas vezes não se sustentavam, pois a docência-sabot buscava não distinguir idades e ano escolar e simplesmente, disparava algo para que todos fizessem suas apropriações. Dessa forma, por mais que o Dispositivo Seriado agisse com força sobre os fazeres e saberes docentes identificamos várias situações em que os professores escapavam de tal força e propunham experiências outras.

Bom, eu acho que até de repente tu já observou, sempre quando passo os conteúdos, na realidade eles estão sempre interligados, tento fazer de uma forma que um ajude o outro em determinados momentos, então esses alunos do primeiro ano eles estavam, vamos dizer assim, em uma atividade deles, contar o valor que eu tinha pedido para eles pegarem... há... sabe contar até quatro, beleza, eu estava aprendendo trabalhando o conteúdo e eu já estava trabalhando com o terceiro, eles tinham que prestar a atenção para ver se o colega tinha contado certo, então eles também estavam voltando ao conteúdo anterior lá deles, eles tinham que prestar a atenção e alertar os colegas que fizeram a contagem errada. [Grifos nossos]

\title{
SUMÁRIO
}

\begin{abstract}
Vamos dizer, não posso passar um problema de multiplicação mais complexa para um aluno de primeiro ano, mesmo sabendo que ele tem condições... Mas eu não posso deixar de provocar ele, ou fazer com que ele em certo momento ajude aquele outro aluno a resolver aquele problema, porque ele também está aprendendo. [Grifos nossos]
\end{abstract}

Agora o pessoal... Aqui vão se reunir os do segundo ano e terceiro, eu divido, tu divides, mas como eu digo, mas ainda há interação entre eles, eu não os impeço de interagirem um com o outro, ou de certa forma. [Grifos nossos]

Dessa forma, o professor não distinguia de forma rígida, as proposições feitas sobre os conteúdos pertinentes a cada série nas aulas de matemática. Pareceu-nos, nas entrevistas, que ele às 
vezes, até tentava separar quando fazia seu planejamento, porém ao executá-lo, a movimentação e o arrastar das cadeiras, fazia com que ocorresse a anulação de uma possível separação. Mengali (2011), na sua dissertação de mestrado, desenvolveu estudos sobre o desafio de ensinar matemática em uma classe multisseriada e por intermédio de sua investigação, afirmou que neste processo, "uma boa tarefa é aquela que possibilita gerar, na sala de aula, momentos ricos de aprendizagem, marcados pela circulação e pela produção de significações matemáticas". (Ibidem, 2011, p.157). Ademais, a autora ressalta que utilizar métodos em que os alunos têm a experiência de trabalhar em conjunto, exercitando o diálogo, com material concreto e fazendo trocas "rompe com a crença de que a melhor maneira de ensinar conceitos matemáticos é partir da explicação clara desses conceitos pelo professor, seguidos da prática deles em exercícios" (MENGALI, 2011, p.177). Em suas observações das aulas de matemática em uma multisseriada a autora sinaliza que:

A construção, no ambiente de sala de aula, de uma comunidade de investigação matemática possibilitou estabelecer com os alunos uma relação de confiança capaz de incentivá-los a protagonizarem os seus próprios processos de aprendizagem, assumindo responsabilidades, ou seja, participando ativamente. (MENGALI, 2011, p.157)

\section{S U MÁRIO}

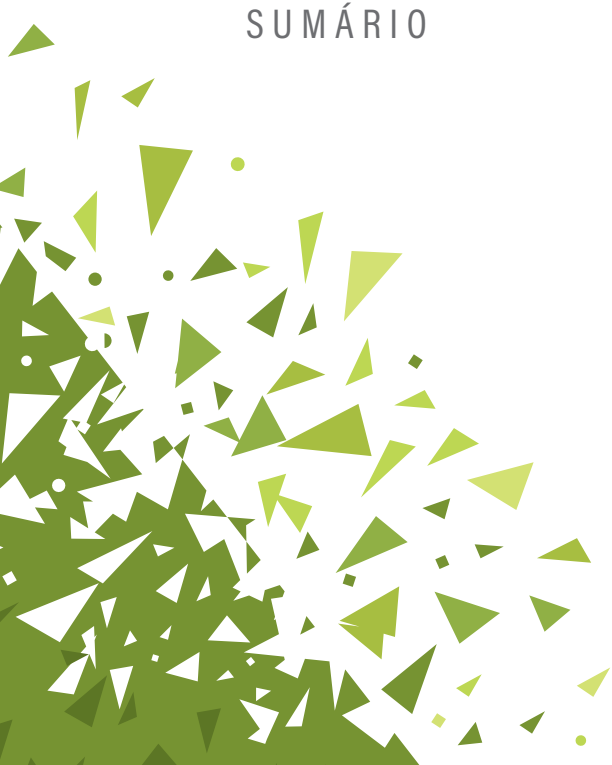

Para sintetizar as discussões empreendidas até aqui, buscamos neste estudo, identificar as formas que fazem germinar as criações e novos modos de fazer educação matemática na organização escolar multisseriada, percebendo dessa forma, essas ações criativas como fissuras na linearidade do currículo de matemática e na organização seriada. Sinalizamos que essa discussão é ampla e complexa, pois as fissuras não se esgotam somente no que nosso olhar se deteve, provavelmente existem outras possibilidades, outras formas que levam os professores a constituir uma docência-sabot. 


\section{Considerações Finais}

Este texto buscou pensar a seriação como um dispositivo que, ao separar as crianças em idade/ano escolar, acaba organizando uma série de elementos para se efetivar e a multisseriação, como um contradispositivo que tende a tensionar a forma de organização de tais elementos. A fim de visibilizar esta tensão, evidenciamos algumas fissuras que ocorreram nas aulas de matemática em uma classe multisseriada, rupturas que foram propiciadas pelos efeitos da heterogeneidade presente no contexto multisseriado.

$\mathrm{Na}$ pesquisa realizada, foram evidenciados atos inventivos dos docentes que, pautados na arte do "tatear", vão construindo outros modos de pensarmos à docência e a educação, mais especificamente a educação matemática. Constitui-se aquilo que denominamos de docência-sabot, uma docência que sabota as estruturas, que atrita as engrenagens da maquinaria escolar, que nos diz o que é válido ou não para o campo educativo. Observamos que o ensino da matemática é tensionado, pois uma concepção muito presente nesta área do conhecimento diz respeito à necessidade de um ensino linear e hierarquizado que respeita a premissa do mais simples ao mais complexo. No entanto, como a sala de aula é habitada por diferentes anos escolares, o professor disponibiliza para a turma (entendida por ele como única) os conteúdos e cada um, a sua maneira, vai se apropriando daquilo que o professor oferece.

Porém, durante as entrevistas, em vários momentos, os professores expressaram suas angustias frente à falta de uma formação específica para um trabalho pedagógico com turmas multisseriadas. Tal fato nos fez inferir que a invisibilidade de discussões, no âmbito dos cursos de licenciatura, tem propiciado a construção de docência inventiva que se produz no exato momento em que se efetua. Dito de outro modo, a falta de manuais de instrução 


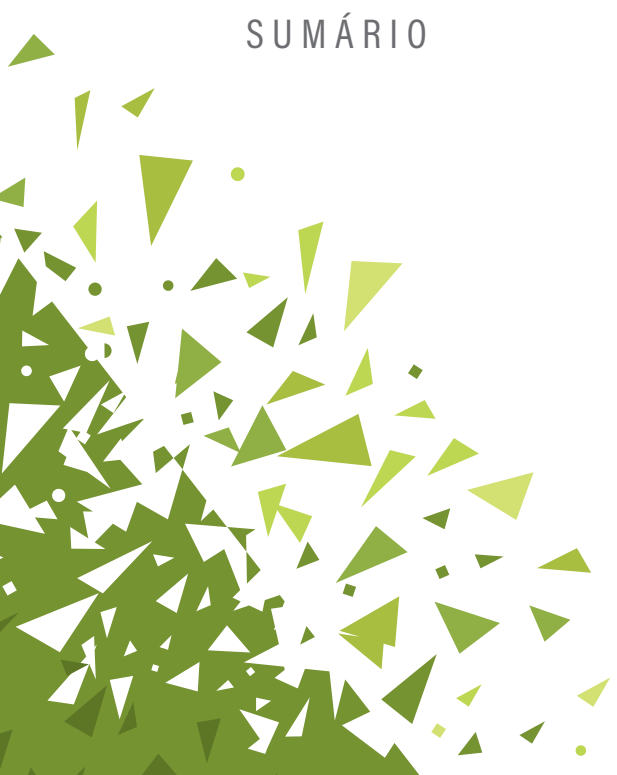

do "faça assim!" tem gerado diferentes experiências educativas que, impulsionadas por movimentos criativos, minimizam a força do Dispositivo da Seriação. Assim, tal lacuna abre espaço para os devires e para a constituição de uma "docência-sabot" que se efetua em um processo de resistência ao que é imposto, pois resistir é "enveredar para outros modos de subjetivação tomando atalhos por onde o discurso que determina a verdade do sujeito não entra". (SOUZA, 2003, p.41). Poderíamos pensar que a docência-sabot permite a configuração de brechas, de um processo educativo ainda sem imagens, pois,

[...] é possível pelas brechas, pelas fissuras em sala de aula, pelo entre lugar, pelo meio da ação educativa, promover processos inventivos e criadores e fazer a diferença escorrer, pois é nesse espaço da fronteira que se pode pensar uma educação em trânsito [...] (BRITO, 2015, p. 35)

É no sentido de perceber esta educação em trânsito que nosso olhar para o campo foi mobilizado. Ao longo da pesquisa, fomos percebendo que a sala de aula multisseriada é um espaço de resistência, pois ela tende a romper com o estabelecido, fazendo com que emerjam movimentos que desestabilizam o que é naturalizado pela maquinaria educacional. Tal condição seria, em nosso entender, propícia para a configuração de novas subjetividades docentes, principalmente para uma docência-sabot que busca fazer arte-arteiramente e que, fazendo força sobre o Dispositivo da Seriação provoca algumas fissuras nas aulas de matemática. Tal condição pode ser propicia para a emergência de outras possibilidades de fazer educação, pareceu-nos existir um processo inventivo, que aberto pelos processos de invisibilização, estimula a criação e libera certos fluxos.

Para finalizar, destacamos que provavelmente as tensões não sejam somente as que, neste trabalho identificamos, mas foi o que vimos, sentimos e interpretamos. Como últimas palavras, 
sinalizamos um desejo: Esperamos que as reflexões empreendidas possam contribuir para que se construam outras percepções sobre as classes multisseriadas, que com uma forma diferente de fazer educação, potencializam a multiplicidade e a diferença.

\section{Referências}

BAUMAN, Zygmunt. Modernidade e ambivalência / Zygmunt Bauman; tradução Marcus Penchel. — Rio de Janeiro: Jorge Zahar Ed., 1999.

BRASIL. Secretaria de Educação Fundamental. Parâmetros curriculares nacionais: matemática / Secretaria de Educação Fundamental. - Brasília : MEC/SEF, 1997

BRITO, Maria dos Remédios de. Entre as linhas da Educação e da diferença. São Paulo: Editora Livraria da Física, 2015.

CORAZZA, Sandra. O que Quer Um Currículo? Pesquisa Pós-Críticas e Educação. Editora Vozes. Petrópolis/ RJ. 2001.

CORAZZA, Sandra Mara; TADEU, Tomaz. Composições. Belo Horizonte: Autêntica, 2003

DELEUZE, Gilles; PARNET, Claire. Diálogos. Trad. Eloísa Araújo Ribeiro. São Paulo: Escuta, 1998

S U MÁRIO

DÍAS, Mario. Foucault, Docentes e Discursos Pedagógicos. Liberdades Reguladas: a pedagogia construtivista e outras formas de governo do eu / Tomaz Tadeu da Silva (org). - Petropólis, RJ: Vozes, 1998.

DUARTE, Claudia Glavam, TASCHETTO, Leonidas Roberto. A Conversar com Estátuas. Currículo sem Fronteiras, v. 14, n. 1, p. 50-61, jan./abr. 2014b. ISSN 1645-1384 (online) www.curriculosemfronteiras.org. Último acesso em 8/03/2018.

FISCHER, Rosa Maria Bueno. Foucault revoluciona a pesquisa em educação? Perspectiva. Florianópolis, v. 21, n. 2, 2003, p. 371-389.

FOUCAULT, Michel. Microfísica do Poder. Rio de Janeiro: Graal, 2000.

FOUCAULT, Michel. A arqueologia do saber. Rio de Janeiro: Forense Universitária, 2008. 
FOUCAULT, Michel. Theatrum Philosophicum. In: FOUCAULT, Michel. Ditos \& Escritos // - Arqueologia das ciências e história dos sistemas de pensamento. Rio de Janeiro: Forense Universitária, 2005.

GALLO, S. Deleuze \& Educação. Belo Horizonte: Autêntica, 2003.

HAGE, Salomão. Transgressão do Paradigma da (multi)seriação como referência para a construção da escola pública do campo. Educ. Soc., Campinas, v. 35, n. 129, p. 1165-1182, out.-dez., 2014.

LARROSA, Jorge. Pedagogia Profana. Belo Horizonte. Profana. 2000.

LARROSA, Jorge. Experiência e Alteridade em Educação. Revista Reflexão e Ação, Santa Cruz do Sul, v.19, n2, p.04-27, jul./dez. 2011.

LOURO, Guacira Lopes. Conhecer, Pesquisar e Conhecer... Universidade Federal do Rio Grande do Sul (UFRGS) (Porto Alegre/Brasil). Educação, Sociedade \& Culturas, $n^{\circ} 25,2007,235-24$.

MENGALI, B. L. S. A cultura da sala de aula numa perspectiva de resolução de problemas: o desafio de ensinar matemática numa sala multisseriada. 2011. 218 f. Dissertação (Mestrado em Educação) - Universidade São Francisco, Itatiba, SP, 2011.

MEYER, Dagmar Estermann, PRAÍSO, Marluci Alves. Metodologias de Pesquisas Pós-críticas ou sobre como fazemos nossas investigações. Dagmar Estermann Meyer Marlucy Alves Paraíso (organizadoras). Metodologias de Pesquisas Pós-críticas em educação. Belo Horizonte: Mazza Edições, 2012.

S U MÁRIO

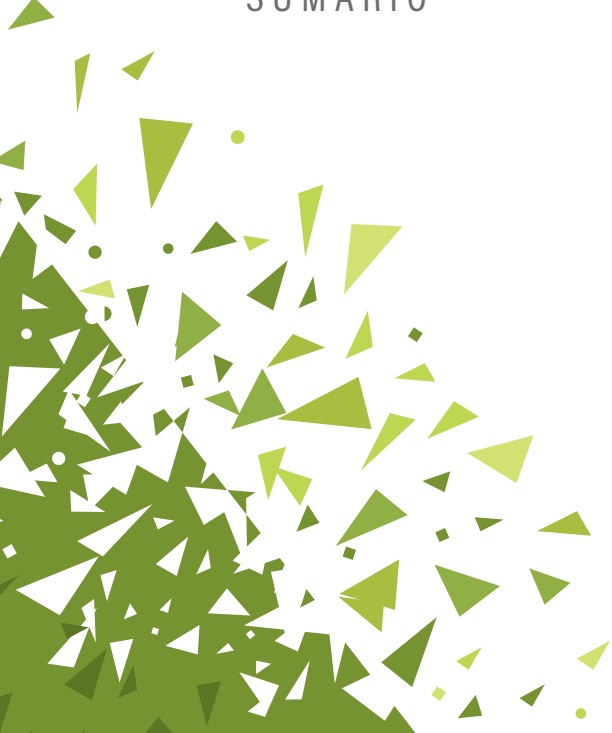

MIZOGUCHI, Danichi Hausen. Amizades Contemporâneas: Inconclusas Modulações de Nós. Danichi Hausen Mizoguchi. Porto Alegre/RS. Sulina, Editora da UFRGS, 2016

NEGRI, A. Exílio. São Paulo: Iluminura, 2001.

SANTOS, Suelen Assunção. Experiências Narradas no Ciberespaço: Um olhar para as formas de se pensar e ser professora que ensina matemática. Dissertação de Metrado pela Universidade Federal do Rio Grande do Sul - UFRGS. Porto Alegre, 2009.

SARTORI, Alice Stephanie Tapia. O lúdico na educação matemática escolar: efeitos na constituição do sujeito infantil contemporâneo. 2015. 158 f. Dissertação (Mestrado em Educação Científica e Tecnológica - Programa de Pós-Graduação em Educação Científica e Tecnológica) Universidade Federal de Santa Catarina, 2015. 
SCHMITZ, Carmen Cecília. Caracterizando a Matemática Escolar. Reflexão e ação: Revista do departamento de educação/UNISC. Vol. 10, n. 1 (jan/ jun. 2002) - Santa Cruz do Sul: EDUNISC. 2002.

SILVA, Tomaz Tadeu. Documentos de Identidade: uma introdução as teorias do currículo. Tomaz Tadeu da Silva, terceira edição. Belo horizonte. Autêntica, 2010.

SILVA, T. T. da. Currículo e Identidade. Social: Territórios Contestados. In: (org.) Alienígenas na sala de aula. Petrópolis - RJ: Vozes, 1998.

SOUZA, Pedro de. Resistir, a que Será que se resiste? O sujeito feito fora de si. In: Linguagem em (Dis)curso. Tubarão, v. 3, Número Especial, p. 37-54, 2003. Sua pesquisa ponto com. Portal de pesquisas temáticas e educacionais. Copyright (c) 2004 - 2017 Sua Pesquisa. Com Todos os direitos reservados. https://www.suapesquisa.com/historia/guerra_de troia.htm Último acesso em: 26/11/2017.

ZORDAN, Paola. Subjetividade na Iniciação à Docência: Personas. Vigésimo segundo encontro anpap 2013. Ecossistemas Estéticos. Belém, Pará. Páginas: 1154 a 1168.

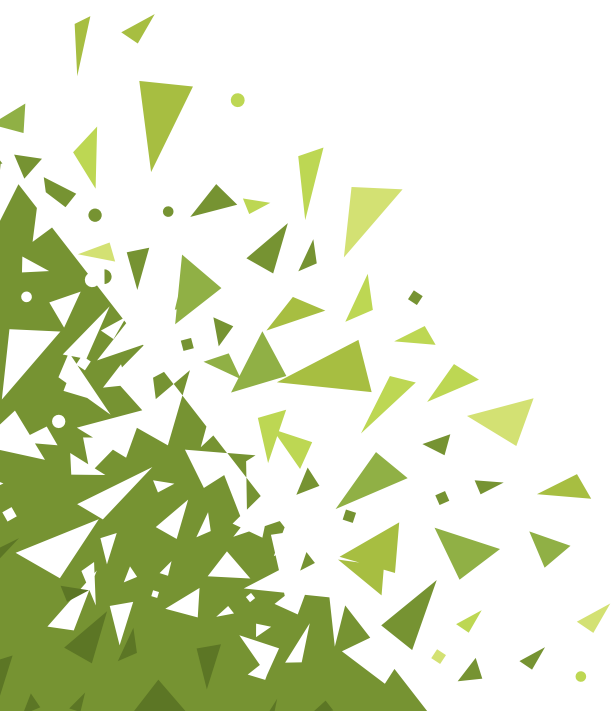

